\title{
Efeito pai professor: \\ o impacto da profissão docente na vida escolar dos filhos
}

\author{
MARLICE DE OLIVEIRA E NOGUEIRA \\ Centro Universitário Metodista Izabela Hendrix
}

\section{INTRODUÇÃO}

Este artigo tem como objetivo divulgar os resultados de uma pesquisa de doutorado recentemente finalizada que investigou as práticas educativas de famílias em que pelo menos um dos progenitores exercia a profissão de professor. A pesquisa buscou identificar, analisar e discutir as múltiplas práticas educativas e estratégias de escolarização que pais professores desenvolvem no quadro da vida escolar de seus filhos.

A hipótese central era a de que o fato de ser professor impacta positivamente as práticas educativas parentais, trazendo benefícios para a escolarização dos filhos. Com essa hipótese, derivada de pistas levantadas por pesquisas realizadas anteriormente, no Brasil e no exterior (Boyer; Delclaux, 1995; Gissot; Héran; Manon, 1994; Langouët; Leger, 2000a, 2000b; Reis, 2006; Santana, 2005; Silva, 2003; Zanten; Duru-Bellat, 1999), pretendeu-se investigar as nuances desse favorecimento, tendo em vista a dinamicidade das práticas educativas familiares.

Os estudos citados anteriormente apontaram que, ora quantitativamente, ora qualitativamente, em relação à escolha do estabelecimento de ensino, os pais professores se encontram em situação privilegiada, por conhecerem profundamente a dinâmica e o funcionamento do sistema escolar. No entanto, esses estudos deixaram lacunas em relação à investigação do interior das práticas educativas em seus múltiplos aspectos. De que modo a posse de um determinado conhecimento do sistema escolar pode favorecer a escolarização dos filhos? Como esses conhecimentos são convertidos em práticas educativas potencialmente favoráveis?

A definição desse objeto de pesquisa está situada no contexto das investigações realizadas no campo da sociologia da educação que remontam ao período posterior 
à Segunda Guerra, em que pesquisas estatísticas, em países como França, Inglaterra e Estados Unidos, apontaram a relação entre pertencimento social e destino escolar. Daquele período até a fase atual das investigações, as pesquisas avançaram no intuito de não apenas identificar ou constatar essa relação, mas principalmente contemplar diferentes variáveis ligadas à família. Isso não somente em relação às características morfológicas e posicionais, mas também sobre as variáveis relacionadas às dinâmicas e processos cotidianos familiares, enfatizados a partir da década de 1980.

Essas variáveis estão relacionadas principalmente ao patrimônio cultural e às expectativas escolares transmitidas aos filhos, aspectos destacados pela teoria da reprodução cultural de Bourdieu $(1964,1966)$. A aplicação desse conjunto de variáveis permite ainda hoje uma compreensão aprofundada da influência da família no desempenho escolar dos filhos (Lareau, 1987) e possibilita um "olhar para o interior", uma investigação que torna visíveis os processos internos das dinâmicas familiares e o seu impacto na vida escolar dos filhos.

A pesquisa foi realizada em Itaúna/MG, município situado a $80 \mathrm{~km}$ da capital mineira, e por meio de um recorte metodológico - professores com formação em nível superior, docência nos anos finais do ensino fundamental e filhos em idade de escolarização (6 a 14 anos) - obteve-se um número (exaustivo) de 114 pais professores investigados.

O percurso investigativo deu-se em duas dimensões: $1^{\circ}$ ) o exame de dados quantitativos coletados por meio de um questionário que permitiu traçar o perfil sociológico dos pais professores $(\mathrm{N}=114)$, mediante a análise de dados demográficos, econômicos, educacionais, profissionais e culturais; e $2^{\circ}$ ) a realização de um total de 80 entrevistas semidiretivas, com uma amostra intencional de 40 pais professores e seus filhos, que possibilitou investigar minuciosamente as práticas educativas e as estratégias de escolarização.

Para identificar, nos dados coletados, as dinâmicas de ação familiar desenvolvidas nos processos de escolarização dos filhos, foram utilizados quatro eixos de análise, definidos por meio de um cruzamento entre o estudo da literatura consagrada sobre o tema, a análise dos dados quantitativos coletados na primeira fase da pesquisa (com os questionários) e os dados qualitativos que emergiram dos contextos dinâmicos das entrevistas realizadas com os pais professores e seus filhos. No primeiro eixo, foram analisados "sentimentos, percepções e expectativas dos pais em relação à escolarização dos filhos"; no segundo, tratou-se das "estratégias de investimento para a construção de projetos de vida para os filhos"; no terceiro, estudaram-se as "práticas concretas de acompanhamento da vida escolar" e, finalmente, "a interação com a escola e com os professores dos filhos".

Uma análise acurada desses eixos desvelou aspectos marcantes que contribuíram para a compreensão das lógicas e dinâmicas parentais em matéria de educação e levaram à configuração de três grupos de pais professores com dinâmicas diferenciadas de ação familiar: "famílias fortemente orientadas para o sucesso escolar" (24 famílias), "famílias fortemente orientadas para a realização pessoal" (9 famílias) e "famílias cujo sucesso escolar depende mais intensamente dos trunfos decorrentes da profissão" (7 famílias). 


\section{DINÂMICAS FAMILIARES: A CONFIGURAÇÃO DE TRÊS GRUPOS DE FAMÍLIAS}

Quem são as famílias pesquisadas? Como podem ser analisadas por suas características demográficas, sociais e culturais? De que modo organizam suas dinâmicas cotidianas? Quais são as práticas e estratégias ${ }^{1}$ colocadas em ação no âmbito familiar com relação aos processos de escolarização da prole?

\section{AS FAMÍLIAS}

As "famílias fortemente orientadas para o sucesso escolar" são, em sua quase totalidade, biparentais, com um ou dois filhos (14 famílias têm 2 filhos, 3 famílias têm 3 filhos e 7 famílias apenas 1 filho). No grupo, são 14 mães professoras e 10 pais professores que atuam profissionalmente em escolas das duas redes, pública e particular. Dos 24 pais professores do grupo, apenas 1 atua somente na rede pública.

Quanto ao perfil socioeconômico das famílias, o quadro a seguir apresenta dados referentes à renda familiar, tipo de moradia e sua localização, posse de bens de consumo e a rede de ensino frequentada pelos filhos.

Quadro 1 - Características socioeconômicas das famílias do grupo 1 ( $\mathrm{N}=24)$

\begin{tabular}{|l|l|}
\hline \multicolumn{1}{|c|}{ Indicadores } & \multicolumn{1}{c|}{ Descrição dos dados } \\
\hline Renda familiar mensal & Entre 3 e 6 mil reais. \\
\hline Moradia das famílias & $\begin{array}{l}\text { 21 famílias possuem imóvel próprio; } \\
\text { 3 famílias residem em moradias alugadas. } \\
\text { As moradias estão localizadas, em sua maioria, no centro da cidade e } \\
\text { em bairros declarados pelos professores como bairros de classe média. } \\
\text { Apenas 2 das 24 famílias contrariam essa regularidade: 1 família mora } \\
\text { em "bairro nobre" da cidade, e outra, em "bairro na periferia”. }\end{array}$ \\
\hline Posse de bens de consumo & $\begin{array}{l}\text { 1 computador em todas as moradias; } \\
\text { Internet banda larga em 20 lares; } \\
\text { TV paga em metade das moradias desse grupo; } \\
\text { Empregada doméstica em 12 famílias; } \\
\text { Posse de sítio, no caso de 2 famílias. }\end{array}$ \\
\hline $\begin{array}{l}\text { Rede de ensino } \\
\text { frequentada pelos filhos }\end{array}$ & $\begin{array}{l}\text { Todos os filhos são escolarizados em estabelecimentos da rede } \\
\text { privada, com mensalidades variando de } \mathrm{R} \$ 200,00 \text { a } \mathrm{R} \$ 429,00 .\end{array}$ \\
\hline
\end{tabular}

Fonte: Questionário aplicado a 114 professores do município de Itaúna/MG, nos meses de abril, maio e junho de 2009. Elaboração da autora.

1 A noção de estratégia utilizada aqui está apoiada nos trabalhos de Pierre Bourdieu (1979, 1980), em que estratégias não são resultado de um “cálculo" totalmente racional, voluntário e consciente, mas também não são fruto de uma "imposição automática” de elementos estruturais, que, sendo inconscientes, não deixariam aos indivíduos nenhuma margem de iniciativa e interpretação pessoal. Elas são a expressão de um "senso prático", um sens du jeu, derivado de uma lógica prática.

2 Segundo informação da Prefeitura Municipal de Itaúna/MG, não há estudo sobre a oferta de serviços e o acesso a eles e sobre a qualidade de vida da população nos diversos bairros da cidade. $\mathrm{O}$ documento Itaúna em dados, publicado pela prefeitura em parceria com a Universidade de Itaúna, apresenta os dados gerais para a totalidade do município, sem especificação para as diferentes regiões da cidade. A classificação "bairro de 
Em relação à família de origem, os pais professores apresentam mobilidade social ascendente, se levarmos em conta o grau de escolaridade e a ocupação de seus progenitores. Porém, o mesmo comportamento não pode ser observado em relação aos cônjuges. Em mais de metade dos casos, os cônjuges possuem, no máximo, o nível médio de escolarização e exercem ocupações como médios empresários e gerentes na indústria, e apenas oito deles possuem formação em nível superior, exercendo profissões liberais.

Uma maior posse de capital econômico, em relação ao grupo anterior, define o grupo composto pelas "famílias fortemente orientadas para a realização pessoal", do qual fazem parte oito mulheres e um homem professores, em arranjos familiares biparentais, sendo que oito famílias têm de um a dois filhos e uma família, três filhos. São pai e mães que vivenciaram também uma mobilidade social ascendente em relação à família de origem. No entanto, mesmo constatada essa mobilidade social e cultural (tendo em vista o capital escolar adquirido) dos pais professores em relação aos seus genitores (sendo que, em quase todos os casos, o pai professor é o primeiro membro da família a cursar o ensino superior), os dados sobre a ocupação exercida pelos genitores revelam que alguns deles tinham atividades que indicam condições econômicas provavelmente favoráveis (um fazendeiro, dois empresários do ramo da siderurgia, um advogado, um bancário e um comerciante).

A tendência a casamentos regressivos observada no grupo 1 , do ponto de vista da escolaridade e da ocupação, não foi observada nesse grupo, tendo os pais professores realizado casamento homogâmico ou ascendente, na medida em que se uniram a pessoas com posição social semelhante ou superior.

Quadro 2- Características socioeconômicas das famílias do grupo 2 (N=9)

\begin{tabular}{|l|l|}
\hline \multicolumn{1}{|c|}{ Indicadores } & \multicolumn{1}{c|}{ Descrição dos dados } \\
\hline Renda familiar mensal & Entre 4 e 8 mil reais. \\
\hline \multirow{3}{*}{ Moradia das famílias } & $\begin{array}{l}\text { As 9 famílias residem em imóvel próprio. Desse grupo, } \\
\text { 4 famílias moram na região central, e 5, em bairros } \\
\text { de classe média ou bairros nobres da cidade. }\end{array}$ \\
\hline & $\begin{array}{l}\text { 1 ou } 2 \text { computadores; } \\
\text { Internet banda larga; }\end{array}$ \\
& $\begin{array}{l}\text { 1 automóvel na garagem; } \\
\text { TV paga na casa de 7 famílias; }\end{array}$ \\
& Empregada doméstica nos 9 lares. \\
\hline $\begin{array}{l}\text { Rede de ensino } \\
\text { frequentada pelos filhos }\end{array}$ & $\begin{array}{l}\text { Em todas as famílias do grupo, os filhos são escolarizados em escolas da } \\
\text { rede particular, com mensalidades variando de R } \$ 200,00 \text { a R } \$ 429,00 .\end{array}$ \\
\hline
\end{tabular}

Fonte: Questionário aplicado a 114 professores do município de Itaúna/MG, nos meses de abril, maio e junho de 2009. Elaboração da autora.

classe média", "bairro nobre" e "bairro em região de periferia" foi retirada dos discursos dos pais professores durante as entrevistas e confirmada por meio de observação direta dos bairros, durante a visita à moradia dos professores. 
As famílias apresentam, conforme demonstrado no Quadro 2, renda familiar oscilando entre quatro e oito mil reais, sendo que três dos pais professores atuam profissionalmente somente na rede particular e os outros nas duas redes de ensino. Podemos supor, portanto, que os pais professores desse grupo desfrutam, de modo geral, de condições materiais e simbólicas de existência relativamente mais favorecidas que aquelas do grupo anterior, constatação permitida não somente pela análise da renda, mas também pela observação de outros aspectos, como o perfil e o local da moradia.

O terceiro grupo é composto pelas "famílias cujo sucesso escolar depende mais intensamente dos trunfos decorrentes da profissão", sendo um pai professor e seis mães professoras. Como nos grupos anteriores, os pais possuem prole reduzida e constituem famílias biparentais.

Quanto à atividade profissional, cinco mães professoras atuam somente na rede pública, sendo que uma mãe e um pai atuam nas duas redes, pública e particular, com carga horária igual ou superior a 32 horas semanais, em disciplinas de matemática, geografia, ciências, português e ensino religioso.

Quadro 3 - Características socioeconômicas das famílias do grupo $3(\mathrm{~N}=7)$

\begin{tabular}{|c|c|}
\hline Indicadores & Descrição dos dados \\
\hline Renda familiar mensal & Renda familiar variando entre 1.900 e 3.800 reais. \\
\hline Moradia das famílias & $\begin{array}{l}4 \text { famílias residem em imóvel próprio adquirido mediante financiamento; } \\
2 \text { famílias moram em casa alugada; } \\
1 \text { família possui imóvel próprio adquirido por herança familiar. }\end{array}$ \\
\hline Posse de bens de consumo & $\begin{array}{l}\text { Todas as famílias possuem computador; } \\
4 \text { famílias possuem internet banda larga; } \\
3 \text { famílias possuem internet discada; } \\
6 \text { famílias possuem automóvel popular com mais de cinco anos de uso; } \\
1 \text { família não possui automóvel; } \\
\text { Não há presença de empregada doméstica nos lares das famílias do grupo. }\end{array}$ \\
\hline $\begin{array}{l}\text { Rede de ensino } \\
\text { frequentada pelos filhos }\end{array}$ & Todos os filhos estudam na rede pública de ensino. \\
\hline
\end{tabular}

Fonte: Questionário aplicado a 114 professores do município de Itaúna/MG, nos meses de abril, maio e junho de 2009. Elaboração da autora.

Os pais desse grupo são originários de famílias cujos progenitores possuem baixo nível de instrução e exercem/exerciam ocupações classificadas como inferiores, como tratoristas, agricultores, ferroviários e serventes. Embora tenha sido constatado que o fenômeno da mobilidade social em relação à família de origem, tendo como via principal a escolarização, se instaura fortemente em todo o universo entrevistado, no caso desse terceiro grupo, a mobilidade social apresenta uma menor extensão. Além disso, a tendência a casamentos regressivos, tanto do ponto de vista ocupacional quanto no que tange ao nível de instrução, é marcante nesse grupo. As seis mães professoras mantêm união estável com cônjuges menos escolarizados (médio e fundamental) e com ocupações classificadas como de nível médio ou inferior (Pastore; Valle Silva, 2000; Scalon, 1999). 
Essa tendência afeta de modo marcante essas famílias, compondo com outros elementos as suas condições materiais e simbólicas de existência. Com a renda familiar declarada (conforme consta no Quadro 3), esses pais professores vivenciam condições objetivas de vida menos favoráveis que as observadas nos outros dois grupos.

\section{PRÁTICAS EDUCATIVAS E A RELAÇÃO COM A ESCOLARIZAÇÃO}

Nas “famílias fortemente orientadas para o sucesso escolar", os pais definem projetos de vida para os filhos, antes mesmo do nascimento, sendo a escolarização a preocupação dominante e inquestionável. Desde a escolha do estabelecimento de ensino ao acompanhamento cotidiano da vida escolar, suas ações e práticas educativas são desenvolvidas com vistas a assegurar a conquista dos mais altos níveis de escolarização para os filhos: uma escolarização longa, em que os estudos superiores sejam realizados em universidades de prestígio. Essas práticas são marcadas por um forte enquadramento ${ }^{3}$ das atividades escolares e extraescolares dos filhos. Muito atentos, esses pais acompanham intensamente a vida escolar da prole e objetivam assegurar o apoio e o acompanhamento pedagógico que consideram necessários e imprescindíveis para o sucesso escolar dos filhos.

Com relação à escolha do estabelecimento de ensino, os pais escolarizam seus filhos na rede particular de ensino e demonstram um forte descontentamento com a escola pública, fundamentado pela própria experiência docente nessas escolas, fenômeno também encontrado na pesquisa de Reis (2006). Esses pais acionam conhecimentos e informações de que dispõem sobre o universo escolar para efetuar boas escolhas, tornando-se bastante aptos a estabelecer contatos diretos ou indiretos com as escolas, com a direção e seus professores. $\mathrm{O}$ critério de escolha mais mencionado pelos pais refere-se à proposta pedagógica e à qualidade de ensino.

No seio das dinâmicas internas dessas famílias, a comunicação e o diálogo são valorizados e têm por objetivo principal a construção de certa "disciplina do esforço" e de uma "dedicação à tarefa", indispensáveis, na visão dos pais, ao sucesso escolar. As crianças são levadas a construir uma autonomia que, paradoxalmente, podemos denominar como "controlada". Os pais professores incentivam os filhos a construir a autonomia na realização das atividades escolares, mas essa autonomia é estritamente controlada e vigiada, no intuito de possibilitar uma ampla gestão dos processos escolares e o controle das escolhas e decisões relativas a esses processos.

Esses pais e mães desenvolvem um "corpo a corpo" no acompanhamento das atividades escolares e extraescolares, verificando-as regularmente. Mesmo que de modo bastante exigente, esses pais esperam dos filhos autonomia e responsa-

3 A noção de enquadramento utilizada nesta pesquisa está apoiada nos trabalhos de Basil Bernstein (1961, 1973, 1998), referindo-se ao grau da força e da visibilidade do controle nas relações sociais. No caso das relações familiares, um enquadramento forte significa um maior controle dos processos educativos por parte dos pais. 
bilidade com as tarefas. Todos (sem exceção) relatam a necessidade de manter a vigilância e de exercer um monitoramento controlado da vida escolar dos filhos. No acompanhamento das tarefas escolares, uma "competência profissional" - tanto em relação aos conhecimentos específicos da sua área de formação e atividade docente quanto dos conhecimentos pedagógicos adquiridos - é mobilizada pelos pais no intuito de apoiar os filhos.

A esse forte monitoramento da vida escolar, comum a muitas outras famílias de classe média, agrega-se um modo de relação com a escola que aqui será chamada de "intervenção direta". Por meio de uma intervenção direta na escola, os pais mobilizam-se na intensão de prevenir ou mesmo sanar possíveis problemas encontrados pelos filhos. Eles consideram ter as competências para definir o tipo de apoio pedagógico necessário para o sucesso dos filhos, e suas intervenções na escola têm geralmente um caráter pedagógico. Estudos anteriores indicam que o exercício da profissão docente dá aos pais professores um conjunto de conhecimentos que lhes permite compreender e definir estratégias para intervir de forma direta na vida escolar dos filhos, quer seja na escola ou no lar (Zanten; Duru-Bellat, 1999; Vieira; Relvas, 2005).

As atividades extraescolares, para esses pais, cumprem uma função lúdica, ao mesmo tempo em que contribuem para a formação geral e estimulam o pensamento e a disciplina. Essa função atribuída pelos pais do meio social mais favorecido às atividades extraescolares foi também identificada nos trabalhos de Zanten e Duru-Bellat (1999) e Kellerhals e Montandon (1991). Zanten e Duru-Bellat indicam que essas práticas, embora se configurem como um "apoio escolar indireto", são muito eficazes para o favorecimento escolar, pois contribuem para desenvolver o "dinamismo e o esforço", atributos bastante valorizados pela escola. Esses pais encorajam seus filhos a praticar atividades que possam desenvolver sua personalidade ou seus "talentos" e assim dotá-los dos "passaportes necessários à sua integração a um meio social particular” (Kellerhals; Montandon, 1991, p. 74, tradução minha).

Em suma, os pais professores dedicam intenso esforço pessoal no intuito de acompanhar a vida escolar dos filhos e para isso se utilizam de diferentes estratégias. Há, portanto, uma rede de diferentes modalidades de apoio escolar que, engendradas, permitem o favorecimento da escolarização dos filhos, o que é comprovado pela inexistência de reprovação e pela ocorrência quase unânime de sucesso escolar no grupo. Terrail (1992) mostra que os destinos escolares são desenhados desde muito cedo e a disposição das crianças aos estudos é dada em razão dos investimentos feitos e da mobilização colocada em ação pelos pais nos processos iniciais de escolarização dos filhos. Concordando com essa premissa, podemos constatar que os filhos desses professores estão em situação de favorecimento desde o ponto de partida na "corrida" da escolarização.

Nas "famílias fortemente orientadas para a realização pessoal", a tônica do discurso dos pais, quando o assunto são as práticas educativas familiares, recai na busca da realização pessoal. Para essas famílias, embora a escola também esteja no centro dos projetos de vida, ela tem uma dupla função: a da instrução, que na visão 
dos pais deve contribuir para desenvolver as potencialidades intelectuais dos filhos, e a da educação numa concepção mais ampla. De acordo com o discurso dos pais, a escola deve contribuir para a "formação da pessoa", para o "desenvolvimento integral", enfim, para uma "realização de si mesmo".

A interpretação dos dados aponta que a busca do "cultivo do eu" está no centro das expectativas de futuro para os filhos. Isso não quer dizer, entretanto, que a escola não seja central em suas aspirações, mas, sim, que ela deve estar integrada aos anseios de desenvolvimento psicológico equilibrado dos filhos.

A dualidade de princípios educativos remete à complexidade da definição do indivíduo contemporâneo, que traz em si duas formas de individualidade: o indivíduo construído pelo seu mérito, pelo desenvolvimento de seus "talentos", e o indivíduo formado pelos laços (de afeto) que o ligam aos outros. Essas duas formas de individualidade produzem diferentes expectativas sociais em relação aos filhos e fornecem aos pais dois princípios educativos: o filho deve ter sucesso; o filho deve ser feliz (Singly, 1996a, 1996b).

Esses princípios marcam fortemente as famílias desse grupo. Para os pais, não é sua única função assegurar a realização pessoal dos filhos, mas também propiciar os meios para que eles possam ser bem-sucedidos na concorrência escolar e profissional. Assim, “obedecer a dois deuses” (Singly, 1996a, p. 139, tradução minha) faz com que os pais e os filhos tenham de resolver, constantemente, situações de contradição: "eu quero que eles pensem em ser uma pessoa realizada", "mas me preocupo com o vestibular também”. Entretanto, a interpretação dos dados também indica que a vivência dessas contradições não impede que as famílias busquem um equilíbrio entre os dois princípios, mesmo que ora privilegiem a dimensão escolar, ora a dimensão psicológica.

Essa dualidade também aparece nos critérios mencionados pelos pais para a escolha do estabelecimento de ensino: "valorização da criatividade e da reflexão" se associa à "proposta pedagógica e qualidade de ensino". São esses pais, no conjunto total das 40 famílias entrevistadas, os que mais optam por escolas menos tradicionais, com "pedagogias invisíveis", nas quais o enquadramento é mais tênue e o papel do professor é propiciar contextos nos quais os discursos e seus significados possam ser criados e recriados pelos alunos (Bernstein, 1977).

Em relação à vida escolar dos filhos, os pais acompanham de perto as suas atividades, exercendo controle e vigilância sobre o tempo, o lugar e o modo como as tarefas são realizadas. Embora esse controle pareça menos rígido - os pais dizem respeitar o "ritmo dos filhos"-, um grau de enquadramento relativamente forte das atividades pôde também ser identificado.

A noção de autonomia - "categoria positiva de percepção do mundo social" (Lahire, 2007, p. 322, tradução minha) - ocupa um lugar central na vida dessas famílias, orientando as práticas educativas parentais, uma vez que os pais, cientes de que a "autonomia do aluno" hoje é evocada pela escola como condição para o sucesso escolar, buscam desenvolvê-la em seus filhos. Por isso mesmo, ao acompanharem de perto a realização das tarefas, os pais sentem-se aptos a realizar um trabalho 
pedagógico que estimule o desenvolvimento das competências consideradas por eles como essenciais para a "construção de si”, para o "desenvolvimento integral da pessoa", para a "fabricação do ser autônomo", e, ao mesmo tempo, buscam preparar os filhos para a concorrência escolar e reparar falhas que o trabalho pedagógico da escola escolhida possa porventura apresentar.

Além disso, aos primeiros sinais de eventuais dificuldades escolares dos filhos - de aprendizagem ou de outro tipo -, a primeira providência desses pais é procurar a escola e os professores. O estreitamento do contato com a escola é, na perspectiva deles, uma condição essencial para prevenir possíveis dificuldades.

Esses genitores também buscam assegurar que o tempo livre seja ocupado com práticas que beneficiem a vida escolar, exercendo a coordenação das atividades escolares e extraescolares. Eles controlam o tempo e o modo como essas práticas extraescolares acontecem, mas permitem certa liberdade de escolha aos filhos no que tange à modalidade. As famílias organizam seu cotidiano em torno da realização de atividades que contribuam para o desenvolvimento de talentos e habilidades que ampliem horizontes e possibilidades futuras (escolar e profissional), realizando um "cultivo orquestrado" da vida da criança (Lareau, 2007).

Observa-se nessas famílias certo diletantismo, que só se torna possível pelo fato de serem dotadas de um volume maior de capital cultural e econômico, o que lhes assegura uma relação mais descontraída e menos tensa com a vida escolar dos filhos. Tendo garantidas as condições da escolha de uma "boa escola" e do sucesso escolar, esses pais sentem-se livres para se ocupar da tarefa de ajudar os filhos numa “construção de si”, na busca da realização pessoal.

O terceiro grupo, composto pelas "famílias cujo sucesso escolar depende mais intensamente dos trunfos decorrentes da profissão", apresenta práticas educativas semelhantes às do primeiro grupo em relação ao acompanhamento e à vigilância das atividades escolares e extraescolares, mas dele se distinguem em dois aspectos: o acompanhamento diário dessas práticas não é tão sistemático e o "corpo a corpo" realizado pelos pais é atenuado. Em contrapartida, os modos de intervenção na escola são mais diretos e incisivos, revelando um nítido processo de "colonização" da escola pública.

No caso dessas sete famílias, todos os filhos estudam em escolas públicas, e a realidade econômica é a justificativa apresentada por todos os pais. No entanto, observa-se que, apesar de a "escolha"4 ser imposta por imperativos financeiros, as famílias não escolhem ao acaso. Esses pais professores escolarizam seus filhos, na maior parte dos casos, na escola em que atuam profissionalmente e, quando isso não é possível, utilizam critérios como informações sobre os professores e a gestão da escola, conhecimento das pessoas, informações sobre o material didático, o nú-

4 As aspas devem-se ao fato de que, na verdade, trata-se de uma "não escolha". Essa noção de "não escolha" refere-se à "escolha do necessário", expressão utilizada por Pierre Bourdieu (1979) para caracterizar a realidade das classes populares que - não tendo poder de escolha - devem limitar-se ao necessário. 
mero e composição das turmas, o clima da escola, disciplina e regras de convivência. Escolarizar o filho na escola em que trabalha possibilita aos pais, além do amplo acesso às informações sobre a escola, que são diretas e contínuas, intervirem, quando necessário, na vida escolar do filho, zelando por seu interesse.

Como se vê, os pais professores, cientes - por dever de ofício - de que a escolarização na rede pública tem deficiências que podem acarretar consequências negativas para a formação dos filhos, se utilizam de estratégias para compensá-las. Os dados mostram um conjunto de estratégias empregado nesse processo de escolarização - colocar os filhos na escola em que trabalha, escolher a turma, ter acesso privilegiado ao material didático, escolher o professor, pedir para trocar de sala, escolher o lugar na sala de aula, fazer exigências - e indicam que os pais se implicam num trabalho de "colonização" (presença intensiva, vigilância, manipulação das situações de interação com os professores e com os contextos de socialização das crianças) (Zanten, 2001, 2009, 2010), de modo que faça com que a escola "funcione" a seu favor, tirando dela a maior rentabilidade possível e reduzindo, em consequência, o "efeito público" (Zanten, 2010, p. 413).

Ao processo de colonização, seria possível acrescentar - no caso dos pais professores - os benefícios que um "ser professor" poderia trazer, as vantagens adquiridas por meio da posse de informações sobre o mundo escolar, que são, nesse caso, convertidas em trunfos, ou seja, em capital. Então, mesmo que desprovidos de outros capitais, como o econômico e o cultural, esses pais professores utilizam o "senso do jogo" construído também no exercício da profissão e, ao fazerem "escolhas", se tornam "bons estrategistas" ou "escolhedores habilidosos" (Gewirtz; Ball; Bowe, 1995), capazes de - apesar de imersos em circunstâncias adversas - fazerem as melhores "escolhas" possíveis.

Submetidos a uma sobrecarga de trabalho, esses pais não conseguem realizar um "corpo a corpo" no acompanhamento diário das tarefas escolares e, por isso, muitas vezes recorrem a outras pessoas, como avós, tios e tias ou vizinhos. Embora esses pais se dediquem a desenvolver nos filhos a autodisciplina e a autonomia, esse trabalho é atenuado, diferentemente dos outros grupos, por ser balizado pelos seguintes aspectos: consciência do menor grau de exigência da escola pública, percepção de que, assim mesmo, os filhos se sobressaem em relação aos seus colegas de turma e ciência da reduzida possibilidade de ingresso dos filhos na universidade pública, restando-lhes a "opção" pelo ensino superior particular.

O que a análise dos dados sugere, de um lado, é que os pais professores, por conhecerem as limitações de uma escolarização na rede pública brasileira, moderam suas expectativas acadêmicas e profissionais para os filhos. Assim, reduzem também, em boa parte, seu nível de exigência quanto ao esforço e à dedicação dos filhos às atividades escolares. Por outro, o estudo revela que eles desenvolvem estratégias tanto de antecipação, como "alfabetizar a criança antes da entrada no ensino fundamental", quanto de compensação: "Vou ensinando algumas coisas que eu sei que a escola não trabalha tanto". Eles levam para os filhos provas e exercícios disponibilizados por outros colegas professores, revisam os conteúdos nos finais de semana, usam as 
provas do Exame Nacional do Ensino Médio (ENEM), com o objetivo de compensar possíveis deficiências do ensino a que são submetidos.

Se partirmos da hipótese bourdieusiana de que as famílias, seja qual for a sua posição de classe, operam um cálculo, em geral tácito - construído por certo "senso do jogo" adquirido -, das probabilidades objetivas de êxito escolar por meio de uma combinação, nunca inteiramente racional, de benefícios, custos e riscos, podemos afirmar que esses pais professores, diante das condições objetivas de vida e das possibilidades vislumbradas para o futuro, desenvolvem suas práticas e estratégias (nem sempre conscientes) no intuito de "dar o mínimo" de um "máximo"idealmente desejado para a escolarização dos filhos.

O que chama a atenção é que eles estão divididos entre o desejo de investir mais na escolarização dos filhos ("eu precisava ajudar mais", "o ideal seria colocar na aula de inglês", "eu quero um dia poder colocar na escola particular") e a angústia advinda do conhecimento que se tem desse "máximo idealizado" e a inevitabilidade de somente poder realizar o "mínimo".

\section{À GUISA DE CONCLUSÃO É POSSÍVEL FALAR DE UM EFEITO PAI PROFESSOR?}

Os resultados revelam claramente que o exercício da profissão de docente favorece o percurso escolar dos filhos e que esse favorecimento se associa à posse de diferentes tipos de vantagens - com especificidade e peso diferenciados em cada grupo investigado -, que contribuem para a constituição de disposições e competências "providas de valor" no mercado escolar.

A primeira constatação é a de que os filhos dos professores pesquisados apresentam uma trajetória escolar regular e, em muitos casos, precoce. No grupo das 40 famílias entrevistadas, não há nenbum caso de reprovação e pouquíssimos casos de recuperação.

As análises realizadas revelam a concentração de competências e disposições favoráveis ao sucesso escolar nas famílias pesquisadas, derivadas de um processo metódico de formação realizado pelos pais, mediante a posse e utilização de alguns trunfos. A coordenação desses trunfos faz dos pais professores tanto "estrategistas privilegiados" quanto "ótimos pais de alunos" e influencia positivamente, favorecendo a vida escolar dos filhos.

Esse favorecimento, evidenciado, no caso deste estudo, pela trajetória escolar de sucesso dos filhos entrevistados, pode ser explicado pela elucidação dos trunfos (advindos do exercício da profissão) utilizados, de modo coordenado, pelos pais.

No que diz respeito à relação com a escola, a rede de contatos construída pelos pais professores, ao longo da carreira profissional e por uma ampla imersão no universo escolar, constitui o que Zanten (2009, p. 135, tradução minha) denomina como "capital social interno à instituição". Essa rede de relacionamentos dá aos pais um trunfo, ou seja, um "capital” bastante rentável. A posse desse "capital" possibilita a construção de "canais de confiança", pelos quais eles têm acesso a informações 
precisas e "quentes" sobre a vida escolar dos filhos e sobre o funcionamento geral da escola (Zanten, 2010, p. 424). O contato que os pais mantêm com os diretores, coordenadores pedagógicos e professores é fundamental, pois lhes permite se beneficiar de informações privilegiadas e intervir mais diretamente nas dinâmicas escolares.

Podemos tomar, como outro dispositivo de conversão das práticas educativas em benefícios para a vida escolar dos filhos, a utilização da "competência" profissional dos pais professores. Essa "competência" reúne conhecimentos científicos específicos da sua área de formação, além de conhecimentos didáticos e pedagógicos. Os relatos revelam que os dois tipos de conhecimento (específico e didático/pedagógico) são mobilizados, mas que o conhecimento didático/pedagógico tem maior peso nas práticas educativas. Os pais professores detêm os métodos e a linguagem mais adequados para fazer com que os filhos compreendam aquilo que eles querem ensinar. Por isso mesmo, eles tornam-se pais "competentes" para ajudar os filhos nos deveres de casa e nos trabalhos escolares e transformam-se em "pais profissionais" porque dominam o "conhecimento escolar", sua natureza e especificidade. Mas, ademais, eles também dominam outros tipos de saberes e informações que os tornam aptos a desenvolver as melhores estratégias educativas.

Bourdieu (1966) afirma que as famílias transmitem às crianças, além do capital cultural, certo éthos, que constitui um sistema de valores tácito e profundamente internalizado, contribuindo para definir o modo da relação com o capital cultural e com a escola. No caso dos pais professores, porque imersos na cultura da escola e atuando diariamente na sua lógica socializadora, eles a conhecem profundamente. Por isso, estão bastante habilitados a desenvolver em seus filhos comportamentos valorizados pela escola: hábitos de estudo, autodisciplina, autonomia, interesses acadêmicos, organização do tempo e do espaço, interiorização de regras.

Ocorre que, se os pais professores estão aptos a entender e a discriminar os comportamentos valorizados pela escola e pelos professores, assim como sua lógica de funcionamento, e se utilizam desse conhecimento em suas práticas educativas, os filhos, por sua vez, também incorporam, profunda e tacitamente, os modos de pensar e sentir próprios da "cultura da escola" (Forquin, 1993), por intermédio de experiências socializadoras nos ambientes familiar e escolar. Assim, essa cultura, profundamente incorporada pelas crianças, passa a compor a imagem construída de si mesmo. Os relatos dos filhos revelam a integração dessa "cultura da escola" aos processos subjetivos de construção do "bom filho", em que as qualidades valorizadas pela escola são incorporadas a essa construção, possibilitando-lhes desenvolver as disposições necessárias ao sucesso (Nicolaci-da-Costa, 1987).

Portanto, a maior evidência consiste na constatação da existência de um "efeito pai professor" (Lasne da Costa, 2011) nos processos de escolarização dos filhos. A ação educativa dos pais professores tem um "efeito" positivo para a vida escolar da prole porque contribui para a construção de "disposições" para o sucesso $\mathrm{e}$, mesmo que essas disposições estejam interligadas umas às outras e, muitas vezes, não possam ser totalmente interpretadas, elas compõem um conjunto que orienta as ações dos sujeitos, levando-os a construir experiências escolares favoráveis. 
É importante destacar que o peso desse efeito não se dá de modo homogêneo, nem com a mesma intensidade nos três grupos. Se, por um lado, foi possível concluir que os pais professores pesquisados, de um modo geral, estão muito bem "equipados" para desenvolver estratégias eficazes para o favorecimento da vida escolar dos filhos, mostrando-se "verdadeiros 'experts' na arte de utilizar o sistema escolar", ao colocarem "o aluno no centro de cálculos e estratégias que visam obter a pequena diferença que faz toda a diferença” (Dubet, 1991, p. 365, tradução minha), por outro, o estudo revela que o peso da profissão docente nas práticas e estratégias educativas das famílias do terceiro grupo é ainda mais impactante, revelando-se em sua plenitude. São esses pais que, desprovidos dos recursos econômicos necessários para fomentar a vida escolar dos filhos, procuram auferir, em grau máximo, os dividendos decorrentes da profissão em benefício da vida escolar destes.

Para esses pais, a intervenção direta na escola acontece de modo incisivo, desde o início da vida escolar, e constitui-se no principal mecanismo para prevenir e compensar as possíveis consequências negativas de uma escolarização na rede pública. Os pais não se sentem constrangidos em revelar comportamentos como: conversar com o diretor a fim de mudar o filho de turma; visitar diariamente a sala dos filhos; solicitar ao professor que o filho se assente sempre na frente; supervisionar o material didático adotado; escolher o colega que vai sentar ao lado do filho; discutir as atividades realizadas; questionar metodologias. Essa desenvoltura - explicada pelo fato de que esse tipo de intervenção é entendido pelos pais como algo "natural" - faz com que a escola funcione, de certo modo, a favor dos filhos. Isso não quer dizer que a "colonização" seja uma estratégia totalmente consciente. Certo é, no entanto, que ela demonstra que os pais construíram, no exercício da profissão, um "sentido do jogo", uma "intuição prática" necessária para agir em benefício da prole. E que, nos casos específicos dessas famílias, o "efeito pai professor" marca, indelevelmente, o destino escolar dos filhos.

\section{REFERÊNCIAS}

BernsteIn, Basil. Social structure, language and learning. Journal of Educational Research, London, v. 3, n. 3, p. 163-176, 1961. . Class, codes and control. London: Routledge and Kegan Paul, v. 1, 1973. . Class and pedagogies: visible and invisible. In: . Class, codes and control.

Towards a Theory of Educational Transmissions. Londres: Routledge \& Kegan Paul, v. 3, 1977. p. $175-192$.

Pedagogía, control simbólico e identidad. Madrid: Ediciones Morata, 1998.

Bourdieu, Pierre. Les héritiers. Paris: Les Éditions de Minuit, 1964.

Lécole conservatrice: les inégalités devant l'école et devant la culture. Revue

Française de Sociologie, Paris, Centre National de la Recherche Scientifique (CNRS), v. II, n. 3, p. 325-347, juil. 1966. 
. La distinction: critique sociale du jugement. Paris: Les Editions Minuit, 1979. . Le sens pratique. Paris: Les Editions Minuit, 1980.

. Coisas ditas. São Paulo: Editora Brasiliense, 1990. . A economia das trocas simbólicas. 5. ed. São Paulo: Editora Perspectiva, 1998.

Bowles, Samuel; Gints, Hebert. Schooling in capitalist America. New York: Basic Books, 1976.

Boyer, Régine; Delclaux, Monique. Des familles face au collége: portraits de groupes. Paris: Institut National de Recherche Pédagogique, 1995.

Dubet, François. Les lycéens. Paris: Seuil, 1991.

Floud, Jean. Social class factors in educational achievement. In: HALSEY, Albert Henry. Ability and educational opportunity. Paris: OCDE, 1961.p. 87-116.

Forquin, Jean-Claude. Escola e cultura. As bases sociais e epistemológicas do conhecimento escolar. Porto Alegre: Artmed, 1993.

Gewirtz, Sharon; Ball, Stephen J.; Bowe, Richard. Markets, choice and equity in education. Buckingham/Philadelphia: Open University Press, 1995.

Gissot, Claude; Héran, François; Manon, Nicole. Les efforts éducatifs des familles. Paris: INSEE, 1994. (Collections INSEE Resultats, Consommation - Modes de vie).

Kellerhals, Jean; Montandon, Cléopâtre. Les strategies éducatives des familles: milieu social, dynamique familiale et education des pré-adolescents. Paris: Delachaux \& Niestlé, 1991.

Lahire, Bernard. L'esprit sociologique. Paris: La Découverte Poche, 2007.

Langouët, Gabriel; Leger, Alain. Public ou privée? Trajectoires et réussites scolaires. Paris: UFR de Sciences de L'Éducation, 2000a. Disponível em: < http://alain-leger. mageos.com>. Acesso em: 29 jun. 2008.

. Le choix des familles: école publique ou école privée? Paris: UFR de Sciences de L'Éducation, 2000b. Disponível em: <http://alain-leger.mageos.com>. Acesso em: 29 jun. 2008.

LAREAU, Annette. Social class differences in family-school relationships: the importance of cultural capital. Sociology of Education, Washington, ASA, v. 60, n. 2, p. 73-85, abr. 1987.

A desigualdade invisível: o papel da classe social na criação dos filhos em famílias negras e brancas. Educação em Revista, Belo Horizonte, Editora da Faculdade de Educação da UFMG, n. 46, p. 32-82, dez. 2007.

Lasne da Costa, Annie. Le réussite scolaire des enfants d'enseignants du primaire à la fin du collège: existe-t-il un "effet enseignant"? In: Colloque "Fabrication Familiale de la Réussite Scolaire D’ajustement aux Publics”. 2011. Paris, Annales... Paris: Université Paris-Dauphine, 2011.

Nicolaci-DA-Costa, Ana Maria. Sujeito e cotidiano. Rio de Janeiro: Campus, 1987.

Nogueira, Maria Alice. Elites econômicas e escolarização: um estudo de trajetórias e estratégias escolares junto a um grupo de famílias de empresários de Minas Gerais. 2002. 
Tese (Concurso Público para Professor Titular) - Faculdade de Educação, Universidade Federal de Minas Gerais, Belo Horizonte, 2002.

Pastore, José; Valle Silva, Nelson do. Mobilidade social no Brasil. São Paulo: Makron Books, 2000.

Prefeitura Municipal de Itaúna. Itaúna em dados. Itaúna, 2008. Disponível em: <www.prefeituramunicipaldeitaúna.com.br>. Acesso em: 4 jun. 2009.

REIs, Rosemeire. Os professores da escola pública e a educação escolar de seus filhos: uma contribuição ao estudo da profissão docente. São Paulo: Paulinas, 2006.

Santana, Regina Palma Azevêdo de. Professor da escola pública: onde estuda seu filho? A família do professor na escolha da escola dos filhos. Tese (Mestrado em Educação) Universidade Católica de Salvador, Salvador, 2005.

Scalon, Maria Celi. Mobilidade social no Brasil: padrões e tendências. Rio de Janeiro: Revan, 1999.

Silva, Pedro. Escola família: uma relação armadilhada - interculturalidade e relações de poder. Porto: Profedições, 2003.

Singly, François de. L'appropriation de l'héritage culturel.Lien Social et Politiques-RIAC, Quebec, RIAC, v. 5, n. 35, p. 153-165, maio 1996a.

. Le soi, le couple et la famille. Paris: Editions Nathan, 1996b.

Terrail, Jean-Pierre. Parents, filles et garçons, face à l'enjeu scolaire. Éducation et Formations, Paris, DEP/MEN, v. 6 , n. 30, p. 3-11, 1992.

Vieira, Cristina Rocha; Relvas, Ana Paula. $A(s)$ vida(s) do professor. Lisboa: Quarteto Editora, 2005.

Zanten, Agnès van. L'école de la périphérie. Paris: Puf, 2001.

. Choisir son école: stratégies familiales et médiations locales. Paris: Presses Universitaires de France, 2009.

. A escolha dos outros: julgamentos, estratégias e segregações escolares. Tradução Maria Amália de Almeida Cunha. Educação em Revista, Belo Horizonte, Editora da Faculdade de Educação da UFMG, v. 26, n. 3, p. 409-433, dez. 2010.

.; Duru-Bellat, Marie. Sociologie de l'école. Paris: Armand Colin, 1999.

\section{SOBRE A AUTORA}

Marlice de Oliveira e Nogueira é doutora em educação pela Universidade Federal de Minas Gerais (UFMG). Professora do Centro Universitário Metodista Izabela Hendrix.

E-mail: nogueira_mar@uol.com.br 


\section{MARLICE DE OLIVEIRA E NOGUEIRA}

Efeito pai professor: o impacto da profissão docente na vida escolar dos filhos

Este artigo pretende divulgar os resultados de uma pesquisa de doutorado recentemente finalizada que investigou as práticas educativas de famílias em que 
pelo menos um dos progenitores exercia a profissão de professor. A pesquisa buscou identificar, analisar e discutir as múltiplas práticas educativas e estratégias de escolarização que pais professores desenvolvem no quadro da vida escolar de seus filhos. Os resultados obtidos mostram que, de um modo geral, os pais professores se mobilizam intensamente para favorecer a escolarização dos filhos, mas que essa mobilização não se dá de modo homogêneo para as diferentes famílias. A origem social, as condições objetivas de existência, a rede de ensino de atuação profissional, as experiências docentes e os modos de configuração das dinâmicas familiares modulam as práticas educativas dos pais professores e impactam a relação que eles estabelecem com a vida escolar dos filhos.

Palavras-chave: pai professor; relação família-escola; práticas educativas.

\section{Teacher parent effect: the impact of having a teacher parent on children's school life}

This paper aims to disseminate the results of a recently completed doctoral research that investigated the educational practices of families in which at least one parent is a teacher. The research sought to identify, analyze and discuss the multiple educational practices and strategies that teacher parents develop as part of the school life of their children. The results obtained show that, in general, parents who are teachers work more intensely on promoting their children's education, but that such work varies from family to family. Social origins, objective living standards, school systems, teaching experience and the different configurations of family dynamics shape the educational practices of such parents and impact on the relationship they establish with their children's school life.

Keywords: teacher parent; family-school relationship; educational practices.

\section{Efecto padre profesor: el impacto de la profésion docente en la vida escolar de sus hijos}

Este trabajo pretende divulgar los resultados de una investigación doctoral recientemente concluida, fundamentada en las prácticas educativas de las familias en las que, al menos, uno de los padres ejercía la profesión docente. La investigación buscó identificar, analizar y discutir las muchas prácticas y estrategias educativas que los padres que ejercen la docencia desarrollan dentro de la vida escolar de sus hijos. Los resultados obtenidos en esta investigación muestran que, de manera general, los padres que ejercen la docencia están más intensamente movilizados para apoyar la enseñanza de sus hijos, pero que esa movilización no se produce homogéneamente entre las distintas familias. El origen social, las condiciones objetivas de existencia, el sistema escolar de desempeño profesional, las experiencias de enseñanza y las diferentes configuraciones de la dinámica familiar afectan a las prácticas educativas de los padres profesores e influyen en las relaciones que establecen con la vida escolar de sus hijos.

Palabras clave: padre profesor; familia-escuela; prácticas educativas. 